\title{
Triptolide as an Alternative to IVIG Therapy for Kawasaki Disease in a Mouse Model
}

\author{
Zong-Ting Yan ${ }^{1}$, Jian-Wen Zou² \\ ${ }^{1}$ Department of Clinical Laboratory, Shandong Province Hospital of Traditional Chinese Medicine, Jinan, China \\ ${ }^{2}$ Department of Clinical Laboratory, Shandong Provincial Hospital, Jinan, China
}

\begin{abstract}
Background: Kawasaki disease is treated by immunoglobulin therapy, which has adverse side effects like renal damage.

Aims: The aim of the present study was to explore the effectiveness of triptolide, a compound derived from threewingnut that has anti-inflammatory effects, on the treatment of Kawasaki disease in a mouse model.

Study Design: Animal experiment.

Methods: A mouse model of Kawasaki disease was established through exposure to Candida albicans by intraperitoneal injection. Exposed mice were then randomly divided into several groups (each $\mathrm{n}=15)$ : model group (saline-treated), low- or high-dose triptolide groups $(0.2 \mathrm{mg} / \mathrm{kg}$ or $0.4 \mathrm{mg} / \mathrm{kg}$, respectively), and IVIG (high-dose immunoglobulin) group (1 g/kg body weight). Unexposed mice served as an additional control group. Nine weeks from the initial exposure, mice were euthanised and coronary tissues and blood samples were harvested. The rate of apoptosis was detected by TUNEL, and ICAM-1 expression was detected by immunohistochemistry in coronary endothelial cells. Serum TNF- $\alpha$ levels were detected by ELISA.
\end{abstract}

Results: Compared to mice in the (unexposed) control group, apoptosis of endothelial cells, ICAM-1 expression, and serum TNF- $\alpha$ levels were significantly increased in all exposed mice $(p<0.05)$, confirming the presence of disease. However, treatment with triptolide or IVIG significantly lowered these measures compared to untreated exposed mice (model group; $p<0.05$ ).

Conclusions: Triptolide treatment reduces markers of coronary endothelial inflammation in a mouse model of Kawasaki disease, similar to IVIG treatment, and therefore may be a useful alternative therapy for this disease.

Key Words: Triptolide, Kawasaki disease, endothelial cells, apoptosis, ICAM-1, TNF- $\alpha$

Received: 21.10.2012

Accepted: 11.03.2013

\section{Introduction}

Kawasaki disease is an inflammatory disorder affecting small blood vessels, and it occurs primarily in children. The condition can have severe cardiovascular complications, and approximately $25 \%$ of untreated children with Kawasaki disease develop coronary artery disease $(1,2)$. Indeed, Kawasaki disease has become one of the major causes of acquired heart disease in children, which can cause sudden death and myocardial infarction during youth and becomes a high-risk factor for ischemic heart disease during adulthood $(3,4)$.

The aetiology of Kawasaki disease remains unknown, but its pathogenesis is characterised by high activation of the immune system and systemic, non-specific vasculitis, with inflammation of the mucus membranes, blood vessel walls, and lymph nodes (1). During vascular inflammation, the absorption of peripheral blood polymorphonuclear leukocytes by endothelial cells occurs via intracellular cell adhesion molecule-1 (ICAM-1) expression in vascular endothelial cells (5). ICAM-1 expression in these cells is significantly increased in children with acute Kawasaki disease (6), and the increased expression contributes to vasculitis. Thus, vascular endothelial ICAM-1 expression can be used as a biomarker of endo- thelial cell activation in the acute phase. Similarly, the cytokine TNF- $\alpha$ is elevated in Kawasaki disease. TNF- $\alpha$ receptors exist on the surface of vascular endothelial cells-those cells affected by the disease. TNF- $\alpha$ has a direct cytotoxic effect on vascular endothelial cells, resulting in vascular endothelial damage (7). This protein can be used as a marker of inflammation in vascular endothelial cells.

The treatment of Kawasaki disease is limited to intravenous injection of high-dose immunoglobulin (IVIG) to combat inflammation. Although the treatment is generally effective, IVIG has drawbacks: application of high-dose IVIG can cause aseptic meningitis (8) and lead to irreversible renal damage (9), and even renal failure (10). In addition, IVIG is expensive. Thus, the development of effective and economical alternative medicines for treating Kawasaki disease has clinical significance.

One potential alternative treatment is the Traditional Chinese Medicine threewingnut root, which possesses both anti-inflammatory and immunomodulatory effects (11). A particular extract from this root, triptolide, can cause apoptosis of lymphocytes activated by human peripheral blood (12). In addition, threewingnut root can inhibit nitric oxide (NO) production by macrophage nitric oxide synthase, and, because

Address for Correspondence: Dr. Zong-Ting Yan, Department of Clinical Laboratory, Shandong Province Hospital of Traditional Chinese Medicine, Jinan, China Phone: +86053168616666 e-mail: zongting0712@126.com 
$\mathrm{NO}$ can induce macrophages to release inflammatory mediators such as TNF- $\alpha$, inhibition of NO production has an indirect immunosuppressive effect (13). These observations have led to speculation that triptolide may be effective in treating Kawasaki disease by reducing inflammation.

Here, a mouse model of Kawasaki disease was established and treated with threewingnut root triptolide. The effects of this extract on coronary endothelial cell apoptosis rate, ICAM1 expression (a marker of Kawasaki disease), and serum TNF- $\alpha$ level (inflammation marker), as well as its effectiveness in treating Kawasaki disease, were investigated.

\section{Materials and Methods}

\section{Kawasaki Disease Mouse Model}

All animal experiments were approved by the Animal Ethics Committee with Identification No. SPHTCM (Ethics) 20101101 and conducted at the Laboratory Animals Care Unit in accordance with the guidelines for the care and use of laboratory animals of Shandong Province Hospital Of Traditional Chinese Medicine. Seventy-five male DBA/2 mice (Experimental Animal Centre of Second Military Medical University) were obtained at 4-5 weeks of age. Mice had an average body mass of $15.30 \pm 0.77 \mathrm{~g}$. Body weights were measured periodically throughout the experiment. A Kawasaki disease model was established according to the methods of Nagi-Miura et al. (14). Briefly, Candida albicans (Guangzhou Microbial Strains Resource Pool) for initial infection were inoculated on prepared culture medium according to methods of Shinohara et al. (15). Five $L$ culture fluid and colonies of $C$. albicans were mixed and aliquoted; aliquots were placed at $37^{\circ} \mathrm{C}$ for 2 days. After 2 days, mixtures were placed in bottles and diluted with equal volumes of ethanol. The next day, sediments were extracted and dried with acetone for use ( $C$. albicans water soluble, CAWS). Next, 60 mice were injected intraperitoneally with $4 \mathrm{mg}$ CAWS continuously for 5 days at the first and fifth week. The 15 remaining mice were intraperitoneally injected with saline during the same period to serve as a control group. At week 8 , mice were grouped according to treatment paradigm. A low-dose group $(n=15)$ received $0.2 \mathrm{mg} / \mathrm{kg}$ threewingnut root triptolide extract (National Institute for the Control of Pharmaceutical and Biological Products of China) by intraperitoneal injection, once per day, continuously for 7 days. A high-dose group $(n=15)$ received $0.4 \mathrm{mg} / \mathrm{kg}$ triptolide extract by intraperitoneal injection once daily for 7 days. An IVIG group $(n=15)$ received IVIG at $L \mathrm{~g} / \mathrm{kg}$ body weight by intraperitoneal injection continuously for 2 days; for five subsequent days, saline was injected. Finally, a model group $(n=15)$ received saline by intraperitoneal injection continuously for 7 days. Mice were observed throughout the treatment period. Blood was collected into EDTA tubes following retro-orbital sampling at week 9, and mice were euthanised for analysis. The heart was perfused with paraformaldehyde and then removed from the body. Coronary tissues were fixed and embedded in paraffin for sectioning. Sections were dewaxed, rehydrated in an ethanol gradient series, and subjected to antigen retrieval at high temperature for subsequent processing.

\section{Detection of Coronary Endothelial Cell Apoptosis}

Apoptotic cells were detected in tissue sections by TUNEL reaction (Wuhan Boster Biological Engineering Co., Ltd., Wuhan, China) according to the manufacturer's instructions. DAB chromogen (Wuhan Boster) was applied to develop staining, and slides were mounted and sealed for analysis by light microscope. The number of apoptotic cells (brown staining) was determined semi-quantitatively, as follows: 5 visual fields were randomly selected at 400x magnification, and 200 nuclei were counted per field. The cell apoptosis rate (percent) was calculated as the number of positive apoptotic cell nuclei / total number of cell nuclei $\times 100$.

\section{Immunohistochemistry}

Tissue sections were incubated in 5\% normal goat serum at room temperature for $30 \mathrm{~min}$. Rabbit anti-rat ICAM-1 antibody (Wuhan Boster) primary antibody was applied to sections. Secondary antibody was applied, and DAB chromogen was added for colour development. As for TUNEL results, 5 high-power fields were randomly selected. Image-pro plus image analysis software was used to determine the average gray value of the positive sites.

\section{Determination of Serum TNF- $\alpha$ Level}

Serum was separated from blood samples by centrifugation. Double-antibody sandwich ELISA (Endogen, USA) was used to determine serum TNF- $\alpha$ levels, according to manufacturer's instructions.

\section{Statistical Methods}

SPSS13.0 statistical software was used for statistical analysis. Measurement data are expressed as mean \pm standard deviation $(\bar{X} \pm s)$. One-way ANOVA analysis of variance was used to compare body weight, coronary endothelial cell apoptosis rate, ICAM- 1 expression, and serum TNF- $\alpha$ levels among control, model (no treatment), low-dose, high-dose and IVIG groups. Pairwise comparison (SNK) was also used for body weight, coronary endothelial cell apoptosis rate, ICAM-1 expression, and serum TNF- $\alpha$ levels between two of the five groups. $p<0.05$ was considered statistically significant.

\section{Results}

\section{Kawasaki Disease Modelling}

No mouse deaths were recorded during the experiment. Mice induced to model Kawasaki disease exhibited disordered fur (white and unglazed), were irritable, and consumed less food and water than mice in the control group, who appeared normal. The accumulation of body weight for mice in the model group was lower during the disease period $(p<0.05)$; however, body weight improved after treatment with threewingnut root triptolide extract or IVIG therapy $(p<0.05)$, although it remained significantly lower than in the control group ( $\mathrm{p}<0.05$; Table 1$)$.

\section{Coronary disease markers following treatment}

Analysis of coronary tissue by TUNEL and immunohistochemistry (Table 2) to measure Kawasaki disease progression 
Table 1. Changes in body weight in mice with and without Kawasaki disease and before/after treatment (g)

\begin{tabular}{|c|c|c|c|c|}
\hline Groups & $\mathbf{n}$ & Day 1 & Week 7 & Week 9 \\
\hline Control & 15 & $15.34 \pm 0.85$ & $25.26 \pm 0.90$ & $27.47 \pm 0.66$ \\
\hline Model (no treatment) & 15 & $15.20 \pm 0.78$ & $21.57 \pm 1.00^{\star}$ & $23.69 \pm 0.80^{\star}$ \\
\hline Low-dose triptolide & 15 & $15.26 \pm 0.68$ & $23.32 \pm 1.16^{\star \Delta}$ & $25.46 \pm 0.92 * \Delta$ \\
\hline High-dose triptolide & 15 & $15.40 \pm 0.90$ & $23.61 \pm 0.89 * \Delta$ & $25.59 \pm 0.97 * \Delta$ \\
\hline IVIG & 15 & $15.31 \pm 0.69$ & $24.12 \pm 0.72^{\star \Delta}$ & $26.09 \pm 0.65^{\star \Delta}$ \\
\hline $\mathrm{F}$ & & 0.144 & 30.279 & 42.029 \\
\hline$P$ & & 0.965 & 0.001 & 0.001 \\
\hline \multicolumn{5}{|c|}{ F represents result of ANOVA. } \\
\hline
\end{tabular}

Table 2. Rates of apoptosis and ICAM-1 expression in coronary endothelial cells in mice with or without Kawasaki disease following treatment

\begin{tabular}{|c|c|c|c|}
\hline Groups & $\mathbf{n}$ & Apoptosis rate (\%) & ICAM-1 \\
\hline Control & 15 & $4.50 \pm 0.25$ & $128.29 \pm 13.68$ \\
\hline Model & 15 & $15.40 \pm 0.31$ * & $176.99 \pm 23.59 *$ \\
\hline Low-dose triptolide & 15 & $7.73 \pm 0.95^{\star \Delta}$ & $158.33 \pm 23.37$ * \\
\hline High-dose triptolide & 15 & $7.54 \pm 1.00 * \Delta$ & $156.11 \pm 23.51$ *॥ \\
\hline IVIG & 15 & $7.24 \pm 0.75^{\star \Delta}$ & $150.91 \pm 25.81^{\star \Delta}$ \\
\hline $\mathrm{F}$ & & 478.508 & 9.167 \\
\hline $\mathrm{p}$ & & 0.001 & 0.001 \\
\hline
\end{tabular}

Table 3. Serum TNF- $\alpha$ levels in mice with Kawasaki disease following treatment $(\mathrm{ng} / \mathrm{mL})$

\begin{tabular}{|lcc|}
\hline Groups & $\mathbf{n}$ & TNF- $\alpha$ \\
\hline Control & 15 & $154.13 \pm 17.42$ \\
Model & 15 & $240.35 \pm 11.60^{\star}$ \\
Low-dose triptolide & 15 & $184.31 \pm 27.61^{\star \Delta}$ \\
High-dose triptolide & 15 & $178.16 \pm 18.19^{\star \Delta}$ \\
IVIG & 15 & $174.97 \pm 20.15^{\star \Delta}$ \\
F & \multicolumn{3}{|}{40.198} \\
P & \multicolumn{3}{|c|}{} \\
\hline p<0.05: *vs. Control group, ${ }^{\mathbf{4}}$ vs. Model group. \\
\hline
\end{tabular}

indicated that mice with Kawasaki disease displayed significantly higher rates of coronary endothelial cell apoptosis rate and ICAM-1 expression compared to mice without induced disease $(p<0.05)$. Additionally, apoptosis rates and ICAM-1 expression in the low-dose triptolide, high-dose triptolide, and IVIG groups were significantly lower than that in the model group (Kawasaki disease but no treatment; $p<0.05$ ). No statistically significant differences were observed among lowdose triptolide, high-dose triptolide, and IVIG groups.

\section{Inflammation Following Treatment}

ELISA was used to detect levels of TNF- $\alpha$ in the sera of mice with Kawasaki disease following treatment, as a marker of inflammation levels. Serum TNF- $\alpha$ levels were significantly higher in mouse models of Kawasaki disease than in controls $(p<0.05$; Table 3). Additionally, the levels of this marker were significantly lower in mice of the low-dose triptolide, highdose triptolide, and IVIG groups than in the model group $(p<0.05)$. No statistically significant difference was observed among low-dose, high-dose, and IVIG groups.

\section{Discussion}

Apoptosis of inflammatory cells, especially neutrophils, is reportedly significantly inhibited in the peripheral blood of Kawasaki disease patients (1). A substantial increase in the number of neutrophils has been observed during the acute phase of the disease, a phenomenon that is accompanied by the formation of toxic particles exiting the nucleus. Importantly, increased neutrophil populations can release large amounts of toxic inflammatory mediators (e.g., oxygen free radicals, elastase) that can cause vascular endothelial damage (6). These observations imply that delayed apoptosis of neutrophil participates in the pathogenesis of Kawasaki disease (16). The administration of IVIG, however, can induce apoptosis of lymphocytes and monocytes (through the Fas pathway). That this treatment resolves Kawasaki disease supports the hypothesis that that delayed apoptosis of lymphocytes and monocytes promotes Kawasaki disease (17). Other treatments that similarly modulate inflammation, while avoiding the adverse effects of IVIG therapy, would be beneficial in the clinical approach to Kawasaki disease.

Here, a mouse model of Kawasaki disease was treated with an alternative therapy, specifically, threewingnut root triptolide extract, which is known to produce anti-inflam- 
matory effects. This treatment was compared with standard IVIG therapy. The rate of apoptosis and expression of ICAM-1 in coronary endothelial cells following triptolide treatment, at either a high or low dose, was essentially equivalent to the rates in mice treated with IVIG. In each of these treatment groups, the rates of apoptosis and ICAM-1 expression were significantly lower than in diseased mice that remained untreated. Similar observations were found for expression levels of TNF- $\alpha$ in sera. In previous studies, triptolide was used to treat mouse models of polycystic kidney disease, and was concluded to be relatively safe (18-20). Therefore, triptolide appears to be a safe and effective alternative treatment for Kawasaki disease. Lowand high-dose triptolide were equally effective (statistical analysis was used to compare parameters between these doses; no differences were observed). Therefore, low-dose threewingnut root triptolide should be further investigated as an alternative therapy, as the lower dose reduces risk of potential adverse effects.

Threewingnut root triptolide may cause apoptosis of lymphocytes activated by human peripheral blood (11) and inhibit nitric oxide synthase of macrophages to generate NO (12), thereby reducing the release of inflammatory mediators and relieving vascular endothelial damage. Previous reports indicate that this compound induces transcriptional arrest and binds to dCTP pyrophosphatase, potentially revealing additional mechanisms of its anti-inflammatory activity $(21,22)$. However, this compound requires further investigation to determine its modes of action.

In summary, threewingnut root triptolide appears to resolve Kawasaki disease endothelial inflammation similar to IVIG therapy, likely by inhibiting the delayed apoptosis of inflammatory cells and lowering endothelial cell ICAM-1 expression. This treatment should be further explored as an alternative to IVIG, which produces equivalent results without the potential adverse effects.

Ethics Committee Approval: Ethics committee approval was received from the Animal Ethics Committee with Identification No. SPHTCM (Ethics) 20101101.

\section{Informed Consent: N/A}

Peer-review: Externally peer-reviewed.

Author contributions: Concept - Z.Y., J.Z.; Design - Z.Y., J.Z.; Supervision - Z.Y., J.Z.; Resource - Z.Y., J.Z.; Materials - Z.Y., J.Z.; Data Collection\&/or Processing - Z.Y., J.Z.; Analysis\&/or Interpretation - Z.Y., J.Z.; Literature Search - Z.Y., J.Z.; Writing - Z.Y.; Critical Reviews - J.Z.

Conflict of Interest: No conflict of interest was declared by the authors.

Financial Disclosure: No financial disclosure was declared by the authors.

\section{References}

1. Kim DS. Kawasaki disease. Yonsei Med J 2006;46:759-72. [CrossRef]

2. Burns JC. The riddle of Kawasaki disease. N Engl J Med 2007;56:659-61. [CrossRef]

3. Hui-Yuen JS, Duong TT, Yeung RS. TNF-alpha is necessary for induction of coronary artery inflammation and aneurysm formation in an animal model of Kawasaki disease with coronary aneurysm in infant. J Immunol 2006;176:6294-301.
4. Satou GM, Giamelli J, Gewitz MH. Kawasaki disease: diagnosis, management, and long-term implications. Cardiol Rev 2007;15:163-9. [CrossRef]

5. Grunebaum E, Blank M, Cohen S, Afek A, Kopolovic J, Meroni $\mathrm{PL}$, et al.The role of anti-endothelial cell antibodies in Kawasaki disease: in-vitro and in-vivo studies. Clin Exp Immunol 2002;130:233-40. [CrossRef]

6. Leung DY, Cotran RS, Kurt-Jones E, Burns JC, Newburger JW, Pober JS. Endothelial activation in the pathogenesis of Kawasaki disease. Trans Assoc Am Physicians 1989;102:131-8.

7. Furukawa S, Matsubara T, Jujoh K, Yone K, Sugawara T, Sasai K, et al. Peripheral blood monocyte/macrophages and serum tumor necrosis factor in Kawasaki disease. Clin Immunol Immunopathol 1988;48:247-51. [CrossRef]

8. Lafferty TE, DeHoratius RJ, Smith JB. Aseptic meningitis as a side effect of intravenous immune gammaglobulin. J Rheumatol 1997;24:2491-2.

9. Levy JB, Pusey CD. Nephrotoxicity of intravenous immunoglobulin. QJM 2000;93:751-5. [CrossRef]

10. Gupta N, Ahmed I, Nissel-Horowitz S, Patel D, Mehrotra B. Intravenous gammaglobulin-associated acute renal failure. Am J Hemato 2001;66:151-2. [CrossRef]

11. Liu MX, Dong J, Yang YJ, Yang XL, Xu HB. Progress in research on triptolide. Zhongguo Zhong Yao Za Zhi 2005;30:170-4.

12. Lin KX, Wang CZ, Qian GS. Effects of triptolide on apoptosis of CD4+ and CD8 + T cells. Immunological J 2000;16:24-6.

13. Wang HL, Yang YJ, He W, Tang DZ, Wang SJ. Effect of triptolide on cytotoxicity and $\mathrm{NO}$ production of activated mouse peritoneal macrophage. Zhonghua Yi Xue Za Zhi 2003;27:237-8.

14. Nagi-Miura $N$, Harada $T$, Shinohara $H$, Kurihara $K$, Adachi $Y$, Ishida-Okawara $A$, et al. Lethal and severe coronary arteritis in DBA/2 mice induced by fungal pathogen, CAWS, Candida albicans water-soluble fraction. Atherosclerosis 2006;186:310-20. [CrossRef]

15. Shinohara $H$, Nagi-Miura N, Ishibashi $K$, Adachi $Y$, Ishida-Okawara A, Oharaseki T, et al. Beta-mannosyl linkages negatively regulate anaphylaxis and vasculitis in mice, induced by CAWS, fungal PAMPS composed of mannoprotein-beta-glucan complex secreted by Candida albicans. Biol Pharm Bull 2006;29:1854-61. [CrossRef]

16. Tsujimoto $H$, Takeshita $S$, Nakatani $K$, Kawamura $Y$, Tokutomi T, Sekine I. Delayed apoptosis of circulating neutrophils in Kawasaki disease. Clin Exp Immunol 2001;126:355-64. [CrossRef]

17. Prasad NK, Papoff G, Zeuner A, Bonnin E, Kazatchkine MD, Ruberti $G$, et al. Therapeutic preparations of normal polyspecific lgG (IVlg) induce apoptosis in human lymphocytes and monocytes: a novel mechanism of action of IVlg involving the Fas apoptotic pathway. J Immunol 1998;161:3781-90.

18. Leuenroth SJ, Bencivenga N, Chahboune H, Hyder F, Crews CM. Triptolide reduces cyst formation in a neonatal to adult transition Pkd1 model of ADPKD. Nephrol Dial Transplant 2010;25:218794. [CrossRef]

19. Leuenroth SJ, Bencivenga N, Igarashi $P$, Somlo S,Crews CM. Triptolide reduces cystogenesis in a model of ADPKD. J Am Soc Nephrol 2008;19:1659-62. [CrossRef]

20. Leuenroth SJ, Okuhara D, Shotwell JD, Markowitz GS, Yu Z, Somlo $S$, et al. Triptolide is a traditional Chinese medicine-derived inhibitor of polycystic kidney disease. Proc Natl Acad Sci USA 2007;104:4389-94. [CrossRef]

21. Corson TW, Cavga H, Aberle N, Crews CM. Triptolide directly inhibits dCTP pyrophosphatase. Chembiochem 2011;12:1767-73. [CrossRef]

22. Leuenroth SJ, Crews CM. Triptolide-induced transcriptional arrest is associated with changes in nuclear substructure. Cancer Res 2008;68:5257-66. [CrossRef] 